\title{
Acute progressive stroke with middle cerebral artery occlusion caused by idiopathic hypereosinophilic syndrome: a case report
}

\author{
Quan-Fu Li, Qing Zhang, Yue-Fang Huang and Zheng-Xiang Zhang ${ }^{*}$ (D)
}

\begin{abstract}
Background: Idiopathic hypereosinophilic syndrome (IHES) is associated with various organ system dysfunctions. Neurologic abnormalities have been previously noted in this syndrome. Cerebral infarction secondary to occlusion of large cerebral artery is rarely reported. Here we described a patient with IHES presented progressive multiple cerebral infarctions caused by bilateral middle cerebral artery occlusion.

Case presentation: A 55-year-old Chinese woman presented to our hospital with acute onset of right limbs weakness and slurred speech. Laboratory tests showed a significant eosinophilia of $5.29 \times 10^{9} / \mathrm{L}$ (normal, <0.5), 49.9\% of leukocytes. Brain magnetic resonance imaging (MRI) revealed multiple acute cerebral ischemic lesions. Magnetic resonance angiography (MRA) demonstrated stenosis in horizontal segment of right middle cerebral artery. A pretibial skin biopsy revealed eosinophilic infiltration around the capillaries in deep dermis and adipose tissue. The patient was given oral dual anti platelet agents and intravenous methylprednisolone. However, one week later, the patient presented significant neurological deterioration with right-sided hemiparesis and totally motor aphasia. Brain MRI and computed tomography perfusion (CTP) demonstrated new acute cerebral ischemia in left hemisphere. Digital subtraction angiography (DSA) revealed left middle cerebral artery completely occluded. The patient received a high-dose of intravenous methylprednisolone $500 \mathrm{mg}$ per day and the eosinophil count quickly fell to normal within 2 days. She was transferred to a rehabilitation center and her neurological symptoms improved with modified Ranking Scale from 4 to 2.
\end{abstract}

Conclusions: IHES is one of the rare causes of acute ischemic stroke with large cerebral artery occlusion. An early high-dose of corticosteroids therapy should be considered in cases of IHES patients. Our case study is benefit to clinical diagnosis and treatment of cerebral infarction with IHES.

Keywords: Idiopathic hypereosinophilic syndrome, Stroke, Middle cerebral artery, MRI

\footnotetext{
*Correspondence: jxzhangzx@163.com

Department of Neurology, The First Affiliated Hospital of Zhejiang Chinese Medical University (Zhejiang Provincial Hospital of Traditional Chinese

Medicine), 54 Youdian Road, Hangzhou 310006, Zhejiang Province, China
}

(c) The Author(s). 2020 Open Access This article is licensed under a Creative Commons Attribution 4.0 International License, which permits use, sharing, adaptation, distribution and reproduction in any medium or format, as long as you give appropriate credit to the original author(s) and the source, provide a link to the Creative Commons licence, and indicate if changes were made. The images or other third party material in this article are included in the article's Creative Commons licence, unless indicated otherwise in a credit line to the material. If material is not included in the article's Creative Commons licence and your intended use is not permitted by statutory regulation or exceeds the permitted use, you will need to obtain permission directly from the copyright holder. To view a copy of this licence, visit http://creativecommons.org/licenses/by/4.0/ The Creative Commons Public Domain Dedication waiver (http://creativecommons.org/publicdomain/zero/1.0/) applies to the data made available in this article, unless otherwise stated in a credit line to the data. 


\section{Background}

Idiopathic hypereosinophilic syndrome (IHES) is a rare disease characterized by an proliferation eosinophil count (greater than $1500 / \mu \mathrm{L}$ ) in the peripheral blood [1]. IHES is associated with various organ system dysfunctions. In addition to cardiac and hematological pathologies, neurological alterations including encephalopathy, sensory polyneuropathy and cerebral infarction have been described [2]. However, Magnetic resonance angiography (MRA) was normal in most cases with IHES presenting ischemic stroke [3, 4]. Large vessel occlusion was rarely reported in patients with IHES. Here we report a middle aged woman presenting IHES and progressive multiple cerebral infarctions with bilateral middle cerebral artery occlusion.

\section{Case presentation}

A 55-year-old Chinese female patient without cerebrovascular risk factors was admitted to hospital with sudden onset of right limbs weakness and slurred speech for 7 days. Her past medical history and family history were negative. She had no history of parasitic infection, allergic diseases and neoplasm. No history of fever, skin rash, joint pains, weight loss, night sweats, diarrhea was noted. She had a standard weight and free of alcohol or illegal drugs use. An initial neurologic examination revealed hemiparesis of right upper and lower extremities (4/5 strength) with extensor plantar response. Obvious pigmentation and nodules were seen in the distal skin of both legs. General medical examination results were normal. Twenty-four-hour ambulatory blood pressure monitoring and Holter recording heart's rate/rhythm were unremarkable.

Blood tests demonstrated a significant eosinophilia of $5.29 \times 10^{9} / \mathrm{L}$ (normal, < 0.5 ), $49.9 \%$ of leukocytes. Autoimmune serum markers and serum parasitic antibody were all negative. No abnormal results was found in serum tumor markers, folic acid, vitamin B12, hemoglobin A1c and oral glucose tolerance test. The screen for fusion gene mutations were normal, including the platelet derived growth factor receptor (PDGFR), fibroblast growth factor receptor 1 (FGFR1), BCR-ABL and JAK2. Bone marrow puncture revealed elevated eosinophils (15\%). A lumbar puncture was performed and cerebrospinal fluid protein was slightly elevated to 45.5 $\mathrm{mg} / \mathrm{dL}$ (normal, <42) with normal pressure $(140 \mathrm{~mm}$ $\mathrm{H}_{2} \mathrm{O}$ ) and cell count. Lung computed tomography scan, abdominal ultrasound, transesophageal echocardiography, contrast transthoracic echocardiography and contrast transcranial Doppler were normal. Brain magnetic resonance imaging (MRI) revealed multiple acute cerebral ischemic lesions (Fig. 1a). Coronal enhanced MRI revealed bilateral middle cerebral artery wall thickening and enhancement (Fig. 1b) and MRA revealed mild stenosis in horizontal segment of right middle cerebral artery (Fig. 1c). A pretibial skin biopsy revealed eosinophilic infiltration around the capillaries in deep dermis and adipose tissue (Fig. 2).

Acute ischemic stroke with IHES was diagnosed. The patient was given oral dual antiplatelet agents, aspirin $100 \mathrm{mg}$ and clopidogrel $75 \mathrm{mg}$ per day and intravenous methylprednisolone $40 \mathrm{mg}$ per day for 5 days.

However, one week later, the patient developed wakeup stroke presenting right-sided hemiparesis (0/5 strength) and totally motor aphasia. Brain MRI and computed tomography perfusion (CTP) demonstrated new acute cerebral ischemia in left hemisphere (Fig. 1de). Digital subtraction angiography (DSA) was performed and M1 segment of left middle cerebral artery were completely occluded (Fig. 1f). We tried to remove the clot with support of vascular stent, but no significant blood clot was removed out. After suction, the inferior branch of left middle cerebral artery restored blood flow (Fig. 1g). Retest of peripheral blood still showed a high eosinophil count of $3.33 \times 10^{9} / \mathrm{L}, 26.4 \%$ of leukocytes. Then the patient received a high-dose of intravenous methylprednisolone $500 \mathrm{mg}$ per day for 4 days. The peripheral blood eosinophil count quickly fell to normal within 2 days $\left(0.07 \times 10^{9} / \mathrm{L}, 0.9 \%\right.$ of leukocytes). She continued oral methylprednisolone $8 \mathrm{mg}$ per day for maintenance.

The neurological symptoms improved slightly and she was referred to a neuro-rehabilitation hospital for treatment. With three months of rehabilitation, her muscle strength of right limbs returned to $3 / 5$ and she could speak short or incomplete sentences. Her activity of daily living improved with modified Ranking Scale from 4 to 2 . The eosinophil count remained in the normal range. However, follow-up MRA still showed bilateral middle cerebral artery branches occlusion (Fig. 1i).

\section{Discussion and conclusions}

Eosinophilia is a hematologic condition with diverse etiologies. The underlying causes are usually classified as reactive (allergic reaction, parasitic infections or tumor), clonal (myeloid leukemia, myeloid neoplasms, or chronic eosinophilic leukemia) and idiopathic [5]. When criteria for HES are met, patients with eosinophilia of unclear cause can be diagnosed clinically as IHES. But it's important to remember that, before making the diagnosis of IHES, all alternative diseases including reactive and clonal causes should be ruled out.

All organ systems are susceptible to the effects of eosinophilia and nearly $65 \%$ of IHES had some neurologic dysfunction [6]. Neurologic involvement in IHES patients is highly variable. Acute ischemic stroke is a common neurological complication caused by IHES. Most previously reported manifestations are mild stroke, 



Fig. 1 Hypereosinophilia with massive cerebral infarction and middle cerebral artery (MCA) occlusion in a 55-year-old woman. Onset Stage: a Diffusion-weighted magnetic resonance imaging (DWI) revealed multiple acute infarcts in right hemisphere. b Coronal enhanced MRI revealed bilateral middle cerebral artery wall thickening and enhancement (red arrows). c MRA showed slightly stenosis in horizontal segment of right MCA. Progression Stage: $\mathbf{d}$ DWI revealed new cerebral infarction in left hemisphere. e CTP showed a significantly longer peak time (TTP) in both hemispheres. $\mathbf{f}$ DSA showed M1 segment of left MCA occlusion. After endovascular therapy, partial MCA recanalization g. Recovery Stage: Brain flair MRI $\mathbf{h}$ demonstrated focal ischemia changes. i Follow-up brain MRA showed bilateral middle artery branches occlusion
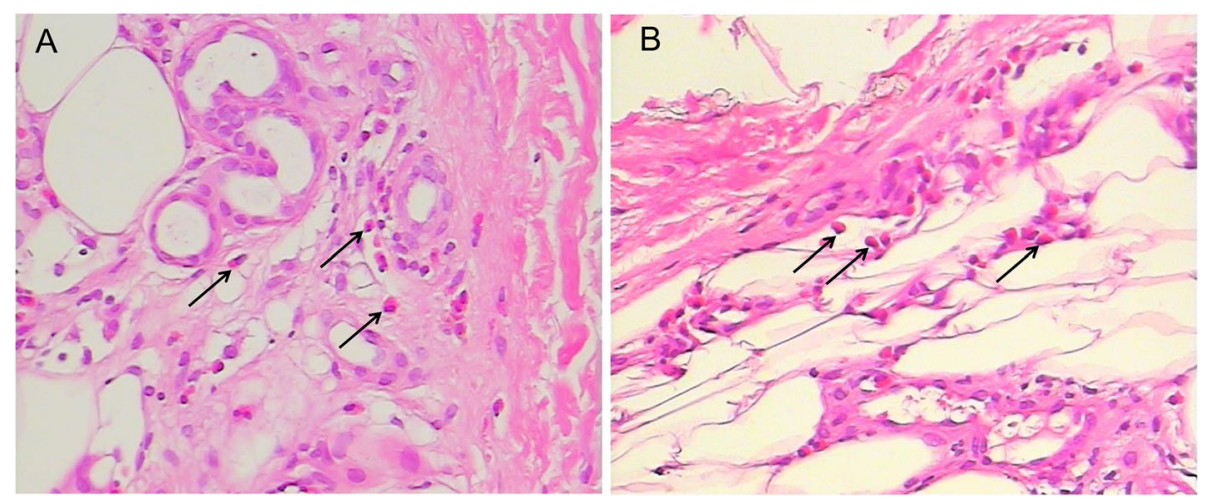

Fig. 2 Light microscopic findings of pretibial skin. a Accumulation of eosinophilia around the capillaries in the deep dermis (arrows, H\&E) . b Infiltration of eosinophilia in the adipose tissue (arrows, H\&E) 
watershed cerebral infarction, and small vascular involvement $[3,4,7-9]$. However, the patient in present study suffered from severe ischemic stroke involving bilateral middle cerebral arteries. As best as we known, there is extremely rare case report of major cerebral artery occlusion in IHES patients. Takeuchi $\mathrm{S}$ reported a 23-year-old female presenting acute ischemic stroke and occlusion of the M1 segment of the left middle cerebral artery resulting from HES [10]. The patient was treated with mechanical thrombolysis and partial recanalization of the left middle cerebral artery was accomplished. Raut TP described a male patient presenting with recurrent strokes over a period of three years, involvement with left and right M1 segment occlusion [11]. Compared to the two cases above, our patient presented with rapidly progressive stroke in a short period and accepted endovascular thrombectomy. Besides, our patient had poor angiogenesis and collaterals, and didn't respond to an initial dose of corticosteroid. For patients of acute ischemic stroke with IHES, thrombolysis or thrombectomy should be administered actively within the time window. Early diagnosis and early use of corticosteroid therapy are crucial.

The mechanism of acute cerebral infarction caused by IHES remains unclear. One major theory is that it is caused by endomyocardial fibrosis and thrombosis [2]. In 52 patients with HES, six patients developed cerebrovascular thromboembolic disease and five of them had heart involvements [6]. However, others hold assumption that cerebral infarction may result from the direct cytotoxic effect of the proteins released by eosinophils and subsequent endothelial damage [12, 13]. This support the manifestations in our patient. Transesophageal echocardiography was did and no evidence of cardiac or aortic mural thrombus was found. In addition, DSA and thrombectomy were performed, which confirm that there was no obvious thrombus formation. Contrast MRI showed bilateral middle cerebral artery wall thickening and enhancement, which support cerebrovascular wall damage inflicted by eosinophilia. Herein, we speculate that vascular inflammation may be the main pathogenesis of progressive cerebral infarction in this case. Unfortunately, no cerebral vascular biopsy was obtained to confirm.

Corticosteroids have been some of the most widely utilized and most effective therapeutic agents in the treatment of IHES. The response to corticosteroid therapy is generally rapid, with reports of eosinophilia resolving within days [14]. However, our patient in present report was unresponsive to methylprednisolone of routine dose. Thus, as the cerebral infarction progressing, high dose of methylprednisolone was given and the eosinophil count quickly returned to the normal range. We recommend that hormone therapy should be administered as soon as IHES is diagnosed to reduce eosinophil levels to normal rapidly. If IHES does not respond well to standard dose of corticosteroids, a highdose of corticosteroids therapy or other immunosuppressive drugs should be considered. Long-term treatment with low dose of steroid or other steroid-sparing medications are required to prevent relapses.

This patient illustrates multiple extensive cerebral infarction and cerebral middle artery occlusion caused by IHES. Accurate diagnosis and prompt treatment are essential. In clinical practice, IHES should also be considered when looking for the cause of cerebral infarction caused by occlusion of the major cerebral artery. Eosinophilia infiltration of cerebrovascular wall may be the main pathogenesis of cerebral infarction in this case. It also underlines the importance of early high-dose corticosteroid therapy in treatment of IHES.

\section{Abbreviations}

CTP: Computed tomography perfusion; DSA: Digital subtraction angiography; FGFR: Fibroblast growth factor receptor; IHES: Idiopathic hypereosinophilic syndrome; MRA: Magnetic resonance angiography; MRI: Magnetic resonance imaging; PDGFR : Platelet derived growth factor receptor

\section{Acknowledgements}

The authors acknowledge Xiaoxiao Shi for her instructive advice in writing the manuscript

\section{Authors' contributions}

QFL, QZ, YFH evaluated and managed the patient. QFL wrote the manuscript and prepared the figures. ZXZ revised the manuscript for important intellectual content and finalized the manuscript. All authors read and approved the final manuscript.

Funding

$\mathrm{n} / \mathrm{a}$

\section{Availability of data and materials}

Data sharing is not applicable to this article as no datasets were generated or analyzed during the current study.

Ethics approval and consent to participate

This case report was approved by the Ethics Committee for clinical medical research of the First Affiliated Hospital of Zhejiang Chinese Medical University.

\section{Consent for publication}

The written informed consent has been obtained from the patient for publication of this case report and any accompanying images.

\section{Competing interests}

The authors declare that they have no competing interests.

Received: 15 May 2020 Accepted: 24 September 2020

Published online: 01 October 2020

\section{References}

1. Simon HU, Rothenberg ME, Bochner BS, Weller PF, Wardlaw AJ, Wechsler $M E$, et al. Refining the definition of hypereosinophilic syndrome. J Allergy Clin Immunol. 2010;126(1):45-9.

2. Curtis C, Ogbogu P. Hypereosinophilic syndrome. Clin Rev Allergy Immunol. 2016;50(2):240-51.

3. Psychogios K, Evmorfiadis I, Dragomanovits S, Stavridis A, Takis K, Kaklamanis $L$, et al. ANCA-negative Churg-Strauss syndrome presenting as acute multiple cerebral infarcts: a case report. J Stroke Cerebrovasc Dis. 2017;26(3):e47-9. 
4. Chen H, Raza HK, Jing J, Shen D, Xu P, Zhou S, et al. Hypereosinophilic syndrome with central nervous system involvement: two case reports and literature review. Brain Inj. 2017;31(12):1695-700.

5. Montgomery ND, Dunphy CH, Mooberry M, Laramore A, Foster MC, Park SI, et al. Diagnostic complexities of eosinophilia. Arch Pathol Lab Med. 2013; 137(2):259-69.

6. Moore PM, Harley JB, Fauci AS. Neurologic dysfunction in the idiopathic hypereosinophilic syndrome. Ann Intern Med. 1985;102(1):109-14.

7. Wise FM, Olver JH. A 66-year-old man with multiple cerebral and cerebellar infarcts due to idiopathic hypereosinophilic syndrome. J Clin Neurosci. 2013; 20(10):1442-3.

8. Wu X, Guo Y, Tan X. Acute cerebral infarction in watershed distribution in a patient with hypereosinophilic syndrome without cardiac lesion. Neurol Sci. 2014;35(10):1607-10.

9. Bolz J, Meves SH, Kara K, Reinacher-Schick A, Gold R, Krogias C. Multiple cerebral infarctions in a young patient with heroin-induced hypereosinophilic syndrome. J Neurol Sci. 2015;356(1-2):193-5.

10. Takeuchi S, Takasato Y, Masaoka H, Hayakawa T, Otani N, Yoshino Y, et al. Middle cerebral artery occlusion resulting from hypereosinophilic syndrome. J Clin Neurosci. 2010;17(3):377-8.

11. Raut TP, Baheti $G$, Raut $S$, Bhattad D, Jain $P$, Jain $A$. A tale of recurrent strokes due to Hypereosinophilic syndrome. Med Clin Rev. 2017;3(3):16.

12. Sethi HS, Schmidley JW. Cerebral infarcts in the setting of eosinophilia: three cases and a discussion. Arch Neurol. 2010;67(10):1275-7.

13. Chang WL, Lin HJ, Cheng HH. Hypereosinophilic syndrome with recurrent strokes: A case report. Acta Neurol Taiwan. 2008:17(3):184-8.

14. Ogbogu PU, Bochner BS, Butterfield JH, Gleich GJ, Huss-Marp J, Kahn JE, et al. Hypereosinophilic syndrome: a multicenter, retrospective analysis of clinical characteristics and response to therapy. J Allergy Clin Immunol. 2009;124(6):1319-25.

\section{Publisher's Note}

Springer Nature remains neutral with regard to jurisdictional claims in published maps and institutional affiliations.

Ready to submit your research? Choose BMC and benefit from:

- fast, convenient online submission

- thorough peer review by experienced researchers in your field

- rapid publication on acceptance

- support for research data, including large and complex data types

- gold Open Access which fosters wider collaboration and increased citations

- maximum visibility for your research: over $100 \mathrm{M}$ website views per year

At $\mathrm{BMC}$, research is always in progress.

Learn more biomedcentral.com/submissions 